\title{
FLORES DE ÉBANO: A EDUCAÇÃO EM TRAJETÓRIAS DE ESCRAVIZADAS E LIBERTAS ${ }^{1}$
}

\section{ALEXANDRA LIMA DA SILVA}

Universidade do Estado do Rio de Janeiro

RESUMO Este trabalho procura analisar a especificidade da condição feminina na escravidão e a inserção da mulher escravizada e liberta no universo da cultura letrada e da educação. A educação foi uma forma de distinção e prestígio? Quais os significados da aquisição dos códigos da cultura letrada para as mulheres escravizadas e libertas? Afinal, o que sabemos sobre a dimensão intelectual na vida das mulheres que vivenciaram o cativeiro? A partir da análise de fontes como autobiografias, relatos de viajantes e periódicos, o trabalho sugere que instruir-se foi uma forma de luta e sobrevivência, em uma sociedade que perseguia, estigmatizava e procurava demarcar, no corpo, no gesto e na fala, a mulher escravizada. Compreendo a educação como uma brecha na conquista da mobilidade e ascensão social, em uma sociedade escravista. A educação pode ter sido também, um caminho para a emancipação de muitas destas mulheres.

Palavras-chave: Mulheres. Escravidão. Educação. Cultura letrada. Emancipação.

\section{ABSTRACT EBONY FLOWERS: EDUCATION IN TRAJECTORIES OF ENSLAVED AND FREEDWOMEN}

This work seeks to analyze the specificity of the female condition in slavery and the insertion of enslaved and freedwomen into the universe of literate culture and education. Was education a form of distinction and prestige? What are the meanings of the acquisition of literate culture codes for enslaved and freedwomen? From the analysis of sources such as autobiographies, travelers' accounts and journals, the work suggests that instruction was a form of struggle and survival in a society which persecuted, stigmatized and sought to demarcate, in the body, in the gesture and speech, the enslaved woman. I understand education as a loophole in gaining mobility and social advancement in a slave society. Education may also have been a way for the emancipation of many of these women.

Keywords: Women. Slavery. Education. Literary culture. Emancipation.

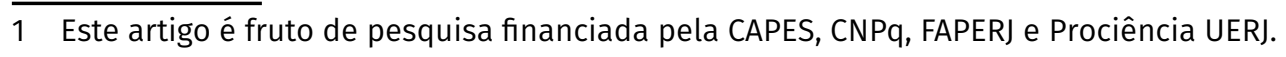




\title{
RESUMEN FLORES DE ÉBANO: EDUCACIÓN EN TRAYECTORIAS DE ESCRAVIZADAS Y LIBERTAS
}

\begin{abstract}
Este trabajo busca analizar la especificidad de la condición femenina en la esclavitud y la inserción de la mujer esclavizada en el universo de la cultura letrada y de la educación. ¿La educación fue una forma de distinción y prestigio? ¿Cuáles son los significados de la adquisición de los códigos de la cultura letrada para las mujeres esclavizadas y libertas? En el análisis de fuentes como autobiografias, relatos de viajeros y periódicos, el trabajo sugiere que instruirse fue una forma de lucha y supervivencia en una sociedad que, que perseguía, estigmatizaba y procuraba demarcar, en el cuerpo, en el gesto y en el habla, mujer esclavizada. Comprendo la educación como una brecha en la conquista de la movilidad y el ascenso social en una sociedad esclavista. La educación puede haber sido también un camino para la emancipación de muchas de estas mujeres
\end{abstract}

Palabras clave: Mujeres. Esclavitud. Educación. Cultura Letrada. Emancipación.

\section{Introdução}

Para justificar a exploração masculina branca e o estupro das negras durante a escravidão a cultura branca teve de produzir uma iconografia de corpos de negras que insistia em representá -las como altamente dotadas de sexo, a perfeita encarnação de um erotismo primitivo e desenfreado. Essas representações incutiram na consciência de todos a ideia de que as negras eram só corpo sem mente. (HOOKS, 1995, p. 469)

Corpos sem mente. Esta é uma representação usual a respeito das mulheres negras escravizadas e libertas. Quando lembradas, são objetificadas. Nas palavras de bell hooks, mesmo "quando eruditos negros escrevem sobre a vida intelectual negra em geral só focalizam as vidas e obras de homens (HOOKS, 1995, p. 466). Tais problemas levam às seguintes indagações: por que tanto silêncio em torno da dimensão intelectual da mulher negra, em especial, escravizada e liberta? Por que uma mulher escravizada não podia ser livre para pensar? Por que não considerar a dimensão intelectual destas mulheres? Por que não se dá visibilidade às diferentes trajetórias de mulheres que, apesar da escravidão, se instruíram e se tornaram autoras da própria história, em primeira pessoa?

Acompanhando bell hooks, os corpos negros femininos "são postos numa categoria em termos culturais tida como bastante distante da vida mental" (HOOKS, 1995, p. 469). A autora sinaliza ainda que dentro das hierarquias de sexo/ raça/classe, as mulheres negras "sempre estiveram no nivel mais baixo. O status inferior nessa cultura e reservado aos julgados incapazes de mobilidade social por serem vistos em termos sexistas racistas e classistas como deficientes incompetentes e inferiores" (HOOKS, 1995, p. 469).

No Brasil, o relato dos viajantes e das viajantes também ajudou a difundir visões de preconceito e depreciação em relação à mulher negra:

As negras maiores também entravam e saíam com um ar negligente, sem se preocupar se estavam perturbando a senhora. Vestiam um traje comprido, em folhos, tão solto que deixavam as 
costas inteiramente descobertas e, por trás, a fenda exibia todo o dorso. As pernas e os pés estavam nus e, no conjunto, embora na realidade estivessem encobertos, não pareciam. (BARONESA DE LANGSDORFF, 1843, p. 72-73).

O fragmento acima é o olhar de uma mulher europeia em relação às mulheres escravizadas no Brasil no século XIX. Tal olhar, carregado de preconceito e depreciação, condenava certa "promiscuidade" no convívio da senhora com a dita "criada de estimação." A Baronesa de Langsdorff ${ }^{2}$ chocava-se principalmente com as vestimentas, descritas como sensuais demais. A ênfase nos aspectos físicos das escravizadas também estava presente nas representações e construções literárias, em que "o corpo da mulher negra foi visto como um misterioso pedaço de carne a ser dissecado" (XAVIER, 2012, p. 67). Outros aspectos referentes à escravizada são: reprodução, família, "as mães pretas", "objeto sexual" (GIACOMINI, 1988).

Nas palavras de bell hooks:

Do outro lado das representações das negras como selvagens sexuais desqualificadas e/ou prostitutas há o estereotipo da mãe preta. Mais uma vez essa imagem registra a presença feminina negra como significada pelo corpo neste caso a construção de mulher como mãe peito amamentando e sustentando a vida de outros. Significativamente a proverbial mãe preta cuida de todas as necessidades dos demais em particular dos mais poderosos. (HOOKS, 1995, p. 469)

A ênfase na sensualidade é outra constante em análises sobre mulheres escravizadas, com destaque para a emblemática figura de Chica da Silva, sobre a qual muito já se falou: nos relatos de viajantes, nas memórias, na literatura, no teatro, cinema e na televisão. Aspectos negativos e muito preconceito compunham as descrições sobre esta mulher, nascida na escravidão, em Minas Gerais, no século XVIII:

2 Victorine Emilie de Sainte-Aulaire nasceu em 1812 e após o casamento com Emile, barão de Langsdorff, no ano de 1834, torna-se a Baronesa de Langsdorff.
Francisca da Silva era uma mulata de baixo nascimento. Fora escrava de José da Silva e Oliveira Rollin, que libertou-a á pedido de João, Fernandes. Tinha as feições grosseiras, alta, corpulenta, trazia a cabeça raspada e coberta com uma cabeleira anelada em cachos pendentes, como então e usava; não possuía graças, não possuía beleza, não possuía espírito, não tivera educação, enfim não possuía atrativo algum, que pudesse justificar uma forte paixão. (SANTOS, 1868, p. 144)

No olhar de Joaquim Felício dos Santos, homem branco do século XIX, Chica da Silva não possuía grandes virtudes, por ele retratada como "iletrada e feia". A visão negativa e pejorativa sobre Chica da Silva permaneceu durante muito tempo, conforme assinalado por Júnia Furtado, para a qual "a historiografia que sucedeu Joaquim Felício dos Santos pouco mudou a imagem de Chica: apenas acrescentou as caracterizações de perdulária, bruxa ou megera" (FURTADO, 2003, p. 269).

Outras construções sobre Chica da Silva dão conta do enriquecimento da liberta, que por meio da relação com um homem branco, tornou-se senhora. Essa é mais uma construção, pejorativa e preconceituosa, bastante difunda. Nascida escrava, Chica da Silva conquistou a liberdade, e tornou-se "Chica que manda", senhora de muitos escravos. No cinema, tornou-se "Xica da Silva" (Cacá Diegues, 1976) e foi interpretada pela atriz Zezé Motta. ${ }^{3} \mathrm{~A}$ atriz também interpreta a alforriada Joana, em outro filme, Quanto vale ou é por quilo (Sergio Bianchi, 2005). Ambos os filmes dão destaque às riquezas materiais obtidas pelas libertas que enriqueceram e se tornaram senhoras de escravos. Todavia, o aspecto intelectual na vida dessas mulheres foi ignorado.

3 Nascida Maria José Motta de Oliveira, em Campos dos Goytacazes, em 1944, Zezé Motta é cantora e atriz, tendo atuado em filmes como: Vai trabalhar, vagabundo (1973), Ouro Sangrento, Anjos da Noite, Tieta do Agreste, Xica da Silva (1976). Ver a biografia: MURAT, Rodrigo. Zezé Motta, muito prazer. Rio de Janeiro: Imprensa Oficial, 2005. 
A historiografia também traz importante contribuição na análise de experiências de libertas que enriqueceram, com destaque às ações das próprias escravizadas, que, por meio do trabalho, ascenderam socialmente, mesmo que isso não significasse usufruir de status (FARIA, 2000). Nas palavras de Sheila Faria, tais mulheres eram:

\begin{abstract}
Amas-de-leite, domésticas, amantes, vendeiras, usurárias, prostitutas, ladras, parteiras, feiticeiras e mais uma variada gama de atividades foram provavelmente desempenhadas pelas mulheres que conseguiram acumular pecúlio ou usaram artimanhas para conseguir sua liberdade. Muitas, não a maioria, tiveram seus nomes inscritos entre os que mais deixaram bens. Enriqueceram, foram donas de escravos, apresentarem-se ataviadas e cheias de jóias nas pequenas e grandes cidades do Brasil escravista. Em momento algum, tanto antes como agora, pela historiografia, puderam usufruir de algum prestígio. (FARIA, 2000, p. 91)
\end{abstract}

O enriquecimento material foi um aspecto importante, contudo, qual o lugar da educação na experiência das mulheres que vivenciaram a escravidão? A educação também não foi vista por tais mulheres como um investimento e uma forma de enriquecimento e distinção, para a conquista da igualdade?

O protagonismo da mulher escravizada é parte do movimento de renovação da própria historiografia, e no entendimento da escravizada e do escravizado, como sujeitos históricos e não "coisas". Neste sentido, destaco trabalhos emblemáticos, como os de Keila Grinberg (1994) e Sandra Lauderdale Graham (2005). Liberata nasceu por volta de 1780 e entrou na justiça com uma ação de liberdade para a conquista da alforria que lhe fora prometida (GRINBERG, 1994). Caetana ousou dizer não ao casamento imposto para ela, o que resulta em um longo processo eclesiástico para a anulação do casamento (GRAHAM, 2005). A presença da mulher escravizada no âmbito da história das mulheres tem ganhado mais destaque. O livro Nova história das mulheres no Brasil (2013), organizado por Carla Pinsky e Joana Maria Pedro, traz o capítulo Escravas, de Maria Odila Dias e Mulheres negras, protagonismo ignorado, de Bebel Nepomuceno. O livro Mulheres negras no Brasil escravista e do pós-emancipação, organizado por Giovana Xavier, Julina Farias e Flavio Gomes (2012) dá visibilidade às diferentes experiências das mulheres negras, incluindo escravizadas e libertas.

O presente trabalho situa-se na área da Educação, num movimento de estudos que exploram as escritas de si, com abordagens e objetivos variados (SOUZA; MIGNOT, 2008; SOUZA, 2006; SOUZA; DEMARTINI; GONÇALVES, 2016). Especificamente no campo da História da Educação, destaco as contribuições de Mignot, Bastos e Cunha (2000), em estudos que evidenciam a consolidação das histórias de vida de professores e escritas de si, num mosaico de diferentes fontes, abordagens e caminhos de pesquisa. Conforme indicado por Barros (2005), o uso de fontes de cunho autobiográfico torna possivel identificar os distintos processos de escolarização e traz à tona a presença negra na escola, que nem sempre era vista de forma otimista ou positiva. Ao explorar o relato autobiográfico de Helena Morley, por exemplo, Surya Pombo de Barros evidencia o olhar receoso da normalista, em ter que lecionar para crianças negras, lamentando: “que será de mim se for obrigada a largar a Escola, estudo, minhas colegas e tudo para ir ensinar a meninos pretos e burros no Rio Grande?" (BARROS, 2005, p. 8). Ou em outro momento, quando explora o relato de Helena Morley, para indicar a existência de professores negros: "como se pode ser tão bom como o nosso professor Dr. Teodomiro!? Depois meu pai ainda diz que gente escura não presta! $\mathrm{Na}$ Escola, pelo menos, os melhores são ele e Seu 
Artur Queiroga. Os brancos são crus de ruindade" (BARROS, 2005, p. 8).

A partir do entendimento da educação como prática para a liberdade, proponho que investir na instrução pode ter sido o caminho para muitas destas mulheres, em busca por prestígio e distinção social, na luta contra o preconceito e o estigma do cativeiro. Para além do en riquecimento material, é possivel pensar outros aspectos almejados por tais mulheres. A educação pode ter sido um caminho para a emancipação de muitas das escravizadas e libertas. Neste sentido, penso a educação não apenas como ascensão social ou mobilidade, mas um caminho para que muitas mulheres que vivenciaram a escravidão registrassem seus anseios, expectativas e lutas. 0 presente trabalho procura dar visibilidade às experiências de mulheres escravizadas e instruídas, aspecto pouco contemplado nas representações e estudos sobre tais mulheres. A educação foi uma forma de distinção e prestígio? Quais os significados da aquisição dos códigos da cultura letrada para as mulheres escravizadas e libertas? Afinal, o que sabemos sobre a dimensão intelectual na vida das mulheres que vivenciaram o cativeiro?

\section{Tão longe, tão perto: condição feminina, educação e escravidão no século XVIII}

O que mulheres como Francisca da Silva, Rosa Egipcíaca, Esperança Garcia e Phillis Wheatley tinham em comum? Nascidas em diferentes lugares, no século XVIII, provavelmente, não se conheceram. Contudo, a experiência do cativeiro as aproxima. Os usos da palavra e da educação também são elos em tais experiências individuais, porém, conectadas.

A respeito de Francisca da Silva de Oliveira, conhecida como "Chica da Silva" ou "Xica da Silva", são muito enfatizados aspectos como sensualidade, enriquecimento material, extravagância e exotismo. Contudo, o estudo de Junia Ferreira Furtado (2003) apresenta aspectos pouco explorados a respeito da escravizada que se tornou senhora: o investimento de Francisca mesma em instrução.

Filha da escravizada Maria da Costa, muIher negra, e de Antonio Caetano de Sá, homem branco, Chica da Silva nasceu no arraial de Milho Verde, em Minas Gerais, no ano de 1734 (FURTADO, 2003, p. 47). Comprada e alforriada por João Fernandes, Chica da Silva tornou-se companheira do contratador dos diamantes, com quem teve treze filhos. Acompanhando a trajetória da liberta, Junia Furtado indica que se em 1753 Chica da Silva era analfabeta, com o passar do tempo a mesma foi se instruindo, passando a frequentar saraus, peças de teatro e apresentações musicais e “também recebeu alguma educação formal que the conferiu a capacidade de assinar seu nome e permitiu distanciar-se de seu passado de escrava e analfabeta" (FURTADO, 2003, p. 184). Educada e instruída, Chica da Silva cuidou com esmero da educação e formação dos filhos e filhas. Os meninos estudavam com professores locais e posteriormente seguiam para continuar os estudos na Europa. Todavia, as filhas de liberta Chica da Silva também estudaram, pois "suas nove filhas foram internadas no Recolhimento de Nossa Senhora da Conceição de Monte Alegre de Macaúbas, o melhor educandário da capitania, onde teriam a garantia de uma vida devota e honrada" (FURTADO, 2003, p. 189). Ainda de acordo com as contribuições de Junia Furtado, é possível saber que três escravizadas pardas acompanhavam as filhas de Chica no Recolhimento de Macaúbas (FURTADO, 2003, p. 194), o que evidencia a possibilidade de que também as escravizadas tenham recebido algum tipo de instrução nesta prática de acompanhar as meninas. 
A presença de escravizadas especificamente no Recolhimento das Macaúbas foi indicada por Leila Algranti, no livro Honradas e devotas: mulheres da colônia, uma vez que com a conivência dos Bispos, as reclusas podiam trazer suas cativas, as quais deveriam ajudar nas tarefas domésticas, bem como, poderiam receber, por tabela, algum tipo de instrução, uma vez que acompanham as reclusas em muitas das atividades (ALGRANTI, 1993, p. 174-176). Outra possibilidade era a presença das filhas ilegitimas, muitas das quais filhas de mulheres escravizadas ou libertas. Este parece ter sido o caso de "Escolástica da Soledade, irmã de hábito nas Macaúbas a partir de 1748. 0 capitão Jorge Rangel aparece ora como pai, ora como padrinho, mas ao final acaba se confirmando a ilegitimidade. A mãe de Escolástica da Soledade era a "preta Eulália'” (ALGRANTI, 1993, p. 137).

Chica da Silva não foi exceção. Outras mulheres escravizadas receberam instrução, no século XVIII. A partir de rica pesquisa documental no Arquivo Nacional Torre do Tombo (Lisboa, Portugal), Luiz Mott desenvolveu importante estudo biográfico sobre Rosa Egipcíaca (17191778). Nascida na África, Rosa foi escravizada aos seis anos de idade e em 1725 chegou ao Rio de Janeiro. Nas palavras de Luiz Mott:

Foi não apenas a primeira africana no Brasil, de quem temos notícia, a conhecer os segredos da leitura, como também provavelmente a primeira escritora negra de toda a história, pois chegou a reunir centenas de páginas manuscritas de um edificante livro Sagrada Teologia do Amor de Deus, Luz Brilhante das Almas Peregrinas, lastimavelmente queimado as vésperas de sua detenção, mas as quais restaram folhas originais. Rosa Egipcíaca é também excepcional por ter sido a única mulher de cor, ex-escrava e ex-prostituta, em todo o mundo cristão, a fundar um 'convento de recolhidas', o Recolhimento de Nossa Senhora do Parto. (MOTT, 1993, p. 8)

Através de processos inquisitoriais e de cartas de Rosa Egipcíaca, dentre outros documen- tos, o livro de Luiz Mott (1993) dá visibilidade à existência de mulheres escravizadas e libertas que sabiam ler e escrever. A aprendizagem da leitura e da escrita "abriu novos horizontes para a negra Rosa", pois "a partir do momento em que se alfabetizou encontrou enorme prazer" (MOTT, 1993, p. 255). Rosa aprendeu a ler e a escrever a partir de passagens de orações, com os ensinamentos de dois mestres: a portuguesa Maria Teresa do Sacramento e José Gomes. Por sua vez, o Recolhimento do Parto idealizado por Rosa era bastante heterogêneo, sendo que as "mulheres de cor" eram quase metade no número de reclusas: "As pretas eram em número de 7: Ana do Santíssimo Coração de Jesus, natural de Vila Rica, do arraial do Padre Faria, tinha 25 anos, sabendo ler e escrever" (MOTT, 1993, p. 301). O recolhimento representou um caminho para que muitas libertas recebessem instrução e conquistassem certa "redenção" em relação aos olhares que associavam as mulheres negras a práticas de luxúria e libertinagem.

Para muitas escravizadas, escrever tornouse, ao mesmo tempo, um ato de repúdio e de expressão, na luta por melhores condições de vida e por direitos. O historiador Luiz Mott (1985) localizou uma carta escrita pela escravizada Esperança Garcia, que, em 1770, escreveu carta de próprio punho para o Governador da Província do Piauí (MOURA, 2004, p. 171). A petição de Esperança para o governador da Gonçalo Lourenço Botelho de Castro, expunha o péssimo tratamento que ela recebeu do capitão Antonio Vieira Couto, inspetor de Nazaré (ROSA, 2012). Na carta, Esperança suplica, “pelo amor de Deus e do seu valimento ponha aos em obrigando digo o procurador que manda para a fazenda onde ele me tirou para eu viver com meu marido e batizar minha filha. De V. ${ }^{\text {a }}$. Sua escrava Esperança Garcia" (MOURA, 2004, p. 171).

No Senegal, África Ocidental, aos sete anos de idade, uma pequena menina foi escraviza- 
da e levada a bordo de um navio para Boston, nos Estados Unidos. A menina recebeu o nome de Phillis Wheatley e tornou-se bastante conhecida por ter escrito o livro Poems on various subjects, religious and moral (1773). Seus primeiros poemas foram escritos aos 14 anos. Phillis Weatley recebeu uma educação diferenciada:

Os escritos de Phillis Wheaatley revelam uma familiaridade com a literatura clássica, pelo menos em tradução, bem como com a geografia, a história, a política e a literatura inglesa, assuntos incomuns para meninas na época. Seu mestre informou em 1772 que ela tinha 'uma grande inclinação para aprender o Latim e fez algum progresso nele'. Alguns críticos modernos foram além do que a evidência permite afirmar que 'ela era uma escrava que conhecia o grego e lia Ovídio no latim original'. (CARRETTA, 2011 p. 40)

Phillis Wheatley é considerada uma pioneira na Literatura Afro-Americana. Em homenagem à poetisa, há uma bela estátua em Boston. Os biógrafos de Phillis Wheatley enfatizam as habilidades acima da média e a inteligência aguçada da menina escravizada. Nas palavras de Vincent Carretta:

Seu apelo é compreensível: o preconceito contra a raça, o status social, o gênero e a idade, apesar disso, em 1773, ela se tornou a primeira pessoa de ascendência africana na América a publicar um livro. A coleção de poemas que ela escreveu em Boston enquanto ela ainda era uma adolescente apareceu pela primeira vez em Londres e fez dela a mais antiga celebridade internacional de ascendência africana. (CARRETTA, 2011, p. 9)

Além de letrada, Phillis Wheatley viajou para London em 1773 e lá conseguiu publicar seu livro de poesias. A liberdade foi conquistada depois disso, no ano de 1778. De escravizada a poetisa, Phillis Wheatley teve uma vida cheia de altos e baixos e, apesar de ter conquistado notoriedade com seu livro e histórias, morreu na obscuridade e na pobreza (CARRETTA, 2011 p. 11).

Apesar de todos os preconceitos e estigmas da escravidão, Francisca da Silva, Rosa Egipcíaca, Esperança Garcia e Phillis Wheatley tiveram suas experiências conectadas pelo fato de terem aprendido a usar a palavra escrita como ferramenta para obter melhorias nas condições de vida, para ascender socialmente, ou, mesmo, para fazer comunicáveis suas experiências e visões de mundo. Foram mulheres do século XVIII. Mas não foram as únicas. Vejamos como as cativas nascidas no século XIX vivenciaram a educação.

\section{Ser autora da própria história: condição feminina e escravidão no século XIX}

Assim como Phillis Wheatley, outra menina africana escravizada foi Josephine Bakhita. Nascida no Sudão, no ano de 1869 , foi sequestrada e escravizada aos nove anos de idade. Conquistou a liberdade em 1889 e, em 1896, tornou-se noviça católica na Itália. Bakhita faleceu em 1947. A escrita de um diário tornou possivel saber um pouco mais sobre Bakhita. Originalmente um manuscrito, foi publicado escrito em 1910 e publicado em 1919 (AKYEAMPONG; GATES JR, 2012, p. 359).

A condição feminina não pode ser ignorada na discussão sobre educação de escravizados. Para a mulher escrava ou liberta, a preocupação com os destinos das filhas era muito grande. Este é outro aspecto importante, conforme argumenta Harriet Jacobs, nascida escrava em 1813, nos Estados Unidos, autora da autobiografia Incidentes na vida de uma escrava, "quando me disseram que o recém-nascido era uma menina, meu coração ficou mais pesado do que nunca. A escravidão é terrível para os homens; mas é muito mais terrivel para as mulheres. Além dos males comuns a todos, 
elas têm males, sofrimentos e mortificações peculiares" (JACOBS, 1988, p. 82).

Harriet Ann Jacobs viveu e morreu no século XIX (1813-1897). Nascida no cativeiro, na região da Carolina do Norte, fugiu para Nova York, em 1842, onde lutou pelo fim da escravidão nos Estados Unidos e fez uso da palavra para contar sua experiência, na forma de autobiografia.

A condição feminina e a especificidade da mulher escrava são marcas fortes no relato de Linda Brent (Harriet Jacobs). A menina escrava muitas vezes servia de boneca para as crianças brancas:

Vi, certa vez, duas belas crianças brincando juntas. Uma era loura e branca; a outra era a sua escrava e também sua irmã. Quando as vi se abraçarem e ouvi sua risada alegre, afasteime com tristeza daquele belo quadro. Previa a desgraça inevitável que cairia sobre o coração da pequena escrava. Sabia como o seu riso se transformaria em soluços dentro em pouco. A criança loura cresceu e transformou-se numa mulher ainda mais bela. Da infância à condição adulta, seu caminho estava cheio e coberto por um céu ensolarado. [...] E como teriam sido esses anos para a sua irmã escrava, a pequena companheira de sua infância? Também era muito bela, mas as flores e o sol do amor não existiam para ela. (JACOBS, 1988, p. 44)

$\mathrm{Na}$ adolescência, muitas escravizadas sofriam com o assédio e a violência sexual por parte dos senhores, e perseguição e ciúme, por parte das senhoras:

Quer a escrava seja negra como ébano ou branca como sua senhora, a situação é a mesma. Em ambos os casos, nenhuma sombra da lei a protege contra insultos, violências e nem mesmo da morte; tudo isso lhe é imposto por demônios que têm a forma de homens. A senhora, que deveria proteger a vítima indefesa, só tem com ela sentimentos de ciúme e raiva (JACOBS, 1988, p. 42).

A escrava mãe, por sua vez, sofria com a separação dos filhos:
Ó felizes mulheres livres, comparem o seu dia do Ano-Novo com o da pobre mulher cativa! Para vocês é uma época agradável, e a luz do dia é bendita [...]. Mas para a mãe escrava o dia do Ano-Novo está carregado de sofrimentos peculiares. Ela fica sentada no frio chão de sua cabana, vendo os filhos que podem ser arrancados dela na manhã seguinte; e com freqüência deseja que possam morrer antes que o dia amanheça. Pode ser uma criatura ignorante, degradada pelo sistema que a brutalizou desde a infância; mas tem o instinto materno e é capaz de sofrear as agonias de mãe. (JACOBS, 1988, p. 33)

Harriet Jacobs não se casou. Envolveu-se com um homem branco da região. Foi mãe solteira de duas crianças. A escrita autobiográfica de Harriet Jacobs é considerada pelo jornal The New York Times "um opúsculo feminista", pois a autora luta duplamente: para libertar-se da escravidão e da opressão contra as mulheres. Harriet Jacobs, em vários momentos, dirigia-se à leitora livre, reconhecendo nas mulheres um vínculo comum: a opressão masculina. Contudo, Harriet enfatizava a especificidade da condição de mulher escrava:

Quando me disseram que o recém-nascido era uma menina, meu coração ficou mais pesado do que nunca. A escravidão é terrivel para os homens; mas é muito mais terrivel para as mulheres. Além dos males comuns a todos, elas têm males, sofrimentos e mortificações peculiares. (JACOBS, 1988, p. 82)

Ainda nas palavras de Harriet Jacobs, é possivel saber que foi educada nos preceitos religiosos e que teve acesso à leitura e à escrita:

Minha senhora ensinara-me os preceitos da $\mathrm{Pa}-$ lavra de Deus... como criança, eu amava muito minha senhora, e relembrando os dias felizes que passei com ela, ensinou-me a ler e escrever, e por esse privilégio, que tão raramente ocorre no destino de um escravo, bendigo sua memória. (JACOBS, 1988, p. 27)

Harriet Jacobs teve dois filhos. A menina foi batizada com o nome de Louisa Matilda Jacobs, 
e nasceu no ano de 1833. ${ }^{4}$ Também nascida no cativeiro, Louisa trilhou o caminho da docência e da militância pela igualdade dos direitos.

Filha de um homem branco com mãe escrava, Louisa teve acesso a uma educação escolar diferenciada e recebeu formação para ser professora. É possivel saber mais sobre as redes de sociabilidade e sobre o pensamento de Louisa, a partir da análise de sua extensa correspondência. Neste sentido, destaco a obra Wispers of cruel wrongs. The correspondence of Louisa Jacobs and her circle, 1879-1911, editada por Mary Maillard, em 2017.

Sem dúvida, o fato de a escravidão seguir o ventre aterrorizava muitas escravizadas. Neste sentido, é preciso cuidado ao analisar as distintas experiências de escravizados e escravizadas. A condição feminina e o fato de a escravidão seguir o ventre são fundamentais e não podem ser ignorados, na luta pela emancipação dos sujeitos, em que o conhecimento da palavra escrita tinha grande força.

Os usos da palavra pelas mães libertas do cativeiro, mas que lutavam pela liberdade de seus filhos e filhas também já foi o foco de estudos acadêmicos (COWLING, 2012; VENANCIO, 2017). Em março de 1886, a liberta Maria Rosa escreveu uma carta para a Imperatriz do Brasil pedindo a carta de alforria para a filha, "pois bem senhora, eu sou mãe de uma infeliz criatura a qual esta quase sempre enferma a ponto de botar sangue pela boca e com três filhos menores e ainda sob o jugo do cativeiro" (Maria Rosa, 1886, Arquivo Geral da Cidade). A carta de Maria Rosa teve êxito, pois a filha Ludovina foi libertada, "talvez por causa da vergonha que a carta de Maria Rosa lhe teria causado" (COWLING, 2012, p. 224).

Outros manuscritos assinados por mulheres escravizadas ou libertas ajudam a compreender o poder da palavra em tempos de

4 Disponivel em: <http://www.blackpast.org/aah/louisa-matilda-jacobs-1833-1917>. Acesso em: 27 mar. 2019 escravidão. Na Biblioteca Nacional, localizei alguns, dentre os quais, a carta da escrava de nome Paula da Cunha Conceição ao imperador, pedindo ser recolhida no Convento da Ajuda, com outra escrava, Felipa, de onde foram expulsas, sem motivos, pela abadessa (Biblioteca Nacional, Manuscritos, fevereiro de 1825). Ou ainda, o requerimento de Mathilde Lauriana, que, em 9 de setembro de 1821, no Rio de Janeiro, assinou de próprio punho o requerimento enviado ao Ministério do Império para embargar a venda de sua filha forra (BN, Manuscritos, 1821). Em 1841, a escrava Ludovina escreveu requerimento solicitando o deferimento de sua permuta com o escravo Domingos de Mariano de Souza Silvino. A escravizada relata que se encontrava enferma e que, por isso, fez compra do escravo Domingos para colocá-lo em seu lugar, em troca de sua liberdade (BN, Manuscritos, 1841). Por seu turno, Benedita, escrava da falecida Maria José do Rosário, em 1858, escreveu um requerimento ao Ministério do Império, solicitando certidões comprovando ter sido alforriada por testamento (BN, Manuscritos - C-0971,017). Madalena, escrava de Ines Felizarda, também enviou requerimento ao Ministério do Império solicitando não ser removida do depósito em que se encontrava, para que pudesse dar seguimento à ação de liberdade intentada contra sua senhora, no ano de 1821 (BN, Manuscritos - C-0530,016). As escravizadas também escreviam para denunciar os maus-tratos sofridos. Este foi o caso de Vitória Maria, escrava parda de Ines Mariana de Araujo, que fez uso da palavra para relatar ao Ministério do Império a crueldade por parte de sua senhora. Solicitava que seu preço fosse posto em juízo e sua carta de alforria fosse passada (BN, Manuscritos, 1850).

O romance ficcional Um defeito de cor, de Ana Maria Gonçalves (2006) nos ajuda a dimensionar um pouco as possibilidades em torno do acesso ao mundo das letras e dos livros. 
A noção de possibilidade, conforme as contribuições do historiador italiano Carlo Ginzburg, é uma categoria fundamental nas análises sobre a condição feminina, pois promove a união entre "erudição e imaginação, provas e possibilidades" (GINZBURG, 2007, p. 311).

Capturada no Daomé, aos oito anos, Kehinda foi escravizada e trazida para o Brasil, por volta de 1818. Na qualidade de acompanhante da sinhazinha, Kehinda, que no Brasil passou a ser chamada de Luiza, recebeu instrução formal nas aulas do professor preto Fatumbi:

No dia seguinte a sua chegada, começaram as aulas para a sinhazinha Maria Clara aprender pelo menos as letras e os números, nos livros e cadernos que foram buscados as pressas na capital. Compraram também tinta, pena e outros apetrechos para a sinhazinha, e um quadro-negro onde Fatumbi ia escrevendo o que ela precisava copiar. As aulas eram dadas na biblioteca, que ficava atrás de uma das portas do imenso corredor, uma que eu nunca tinha visto aberta antes. Fiquei feliz por poder assistir as aulas na qualidade de acompanhante da sinhazinha, e tratei de aproveitar muito bem a oportunidade. (GONÇALVES, 2006, p. 192)

Luiza passou a estudar de forma apaixonada e interessada, diferente da própria sinhazinha: "Eu e a sinhazinha passávamos a maior parte do tempo no quarto, ela fingindo estudar e eu estudando de fato, com os livros que não estavam em uso" (GONÇALVES, 2006, p. 193).

A personagem Kehinda/Luiza foi inspirada em Luíza Mahin, mãe de Luiz Gama. Vendido ilegalmente como escravo pelo pai, ainda na infância, conquistou a alforria e tornou-se importante jornalista e defensor dos escravizados no Brasil Império (AZEVEDO, 1999; SOUZA, 2001).

Em carta autobiográfica, Luiz Gama fala da mãe, "Sou filho natural de uma negra, africana, livre, da Costa da Mina (Nagô de nação) de nome Luiza Mahin, pagã, que sempre recusou o batismo e a doutrina cristã" (GAMA, 1882 apud SCHWARCZ, 1989, p. 10). Luiz Gama escreveu uma carta para falar de si, mas também, sobre sua mãe, que também era letrada.

A partir da autobiografia do liberto Israel Soares, também é possivel saber sobre a dor de uma mãe que precisou escolher entre a liberdade do filho ou da filha. Segundo Israel Soares, a "mãe foi mais feliz do que meu pai, pois conseguiu libertar-se em 1846, graças aos esforços de um preto mina chamado Antonio" (SOARES apud SENA, 1983, p. 139). Luiza, na condição de preta forra e quitandeira, era maometana. Juntou dinheiro e comprou a liberdade da irmã de Israel, em 1856: "mulata, que ainda hoje vive cheia de filhos e netos" (SOARES apud SENA, 1983, p. 140). Luiza, preta mina forra, optou por comprar a liberdade da filha, em detrimento da alforria do filho, pelo fato de aquela ser mulher e, uma vez que a escravidão seguia o ventre, de acordo com a legislação vigente, e no entendimento de Luiza, a filha merecia proteção maior.

\section{Considerações finais}

Este trabalho procurou dar visibilidade às trajetórias de mulheres que vivenciaram a escravidão, em diferentes lugares e períodos históricos. Em termos metodológicos, optei por inventariar as trajetórias a partir de importantes estudos já produzidos sobre mulheres escravizadas. Também analisei fontes por mim mapeadas, dentre as quais, relatos de viajantes, manuscritos, periódicos e autobiografias.

A partir da análise de fontes variadas, é possível vislumbrar a inserção da mulher escravizada e liberta no universo da cultura letrada e da educação e de como o acesso à palavra escrita representou, para muitas, a possibilidade de "fazer comunicável sua memória e experiência" (MARTIN-BARBERO, 2001, p. 179). As escravizadas não eram coisas. Eram complexas, ricas em experiências e anseios (SILVA, 2014). 
Dentre as conclusões possíveis, destaco a complexidade em torno do ser mulher e escravizada nos séculos XVIII e XIX. O acesso à palavra escrita, por diferentes caminhos, significou uma tomada de consciência em relação aos horrores da escravidão, principalmente para uma mulher. Escrever, em primeira pessoa, foi uma estratégia de sobrevivência, no plural, uma vez que muitas mulheres escreviam no sentido de lutar pela liberdade daquelas que ainda estavam no cativeiro. Escrever sobre si, mas não somente para si. Escrever para transgredir, para libertar. E floresceram.

\section{Referências}

ALGRANTI, Leila. Honradas e devotas: mulheres da colônia. São Paulo: Hucitec; Fapesp, 1993.

AKYEAMPONG, Emanuel; GATES JR, Henry. Dictionary of african biography. Oxford: Oxford University Press, 2012.

ARQUIVO GERAL DA CIDADE, Rio de Janeiro, Carta Maria Rosa, 1886.

AZEVEDO, E. Orfeu de Carapinha: A trajetória de Luiz Gama na imperial cidade de São Paulo. Campinas, Ed. da Unicamp, 1999.

BARROS, S. Negrinhos que por ahi andão: escolarização da população negra em São Paulo (18701920). 2005. 175f. Dissertação (Mestrado em Educação) - Faculdade de Educação, Universidade de São Paulo, São Paulo, 2005.

CARRETTA, Vincent. Phillis Wheatley: biography of a genius in bondage. Athens, Ga: University of Georgia Press, 2011.

COWLING, Camillia. O fundo de emancipação "Livro de Ouro" e as mulheres escravizadas: gênero, abolição e os significados da liberdade na Corte, anos 1880. In.: XAVIER, Giovana; FARIAS, Juliana; GOMES, Flávio. (Orgs.). Mulheres negras no Brasil escravista e do pós-emancipação. São Paulo: Selo Negro, 2012, p.214-227.

DIAS, Maria Odila. Escravas. Resistir e sobreviver. In:
PINSKY, Carla; PEDRO, Joana. (Orgs.). Nova história das mulheres no Brasil. São Paulo: Contexto, 2013. p. 360-381.

FARIA, Sheila. Mulheres forras - Riqueza e estigma social. Tempo, Niterói, RJ, v. 5, n. 9, p. 65-92, 2000.

FURTADO, Júnia Ferreira. Chica da Silva e o contratador de diamantes. 0 outro lado do mito. São Paulo: Companhia das Letras, 2003.

GIACOMINI, S. M. Mulher e escrava: uma introdução histórica ao estudo da mulher negra no Brasil. Petrópolis, RJ: Vozes, 1988.

GINZBURG, Carlo. Apêndice-Provas e possibilidades. In: _____ 0 fio e os rastros: verdadeiro, falso, fictício. São Paulo: Cia. das Letras, 2007. p. 311-338.

GONÇALVES, Ana Maria. Um defeito de cor. São Paulo: Record, 2006.

GRAHAM, Sandra Lauderdale. Caetana diz não. Histórias de mulheres da sociedade escravista brasileira. São Paulo: Cia. das Letras, 2005.

GRINBERG, K. Liberata: a lei da ambiguidade - As ações de liberdade da Corte de Apelação do Rio de Janeiro no século XIX. Rio de Janeiro: Relume-Dumará, 1994.

HOOKS, bell. Intelectuais negras. Estudos Feministas, v. 3, n. 2, p. 464-478, 1995.

JACOBS, Harriet. Incidentes na vida de uma escrava, contados por ela mesma. Rio de Janeiro: Campus, 1988.

LANGSDORFF, Baronesa Emile de. Diário da Baronesa E. de Langsdorff. Relatando sua viagem ao Brasil por ocasião do casamento de S. A. R. o Príncipe de Joinville, 1842-1843. Florianópolis: Editora Mulheres, 1999.

MAILLARD, Mary. Wispers of cruel wrongs. The correspondence of Louisa Jacobs and her circle, 18791911. Madison: Wisconsin Studies in Autobiography; University of Wisconsin Press, 2017.

MARTIN-BARBERO, Jesus. Dos meios às mediações. Rio de Janeiro: Editora da UFRJ, 2001.

MIGNOT, Ana C. V.; BASTOS, Maria Helena C.; CUNHA, Maria Teresa Santos (Orgs.). Refúgios do eu: educa- 
ção, história, escrita autobiográfica. Florianópolis: Editora Mulheres, 2000.

MOTT, Luiz. Rosa Egipcíaca: uma santa africana no Brasil. Rio de Janeiro: Editora Bertrand Brasil, 1993.

MOTT, Luiz. Piauí colonial: população, economia e sociedade. Teresina: Projeto Petrônio Portela; Governo do Estado do Piauí, 1985.

MOURA, Clóvis. Dicionário da escravidão negra no Brasil. São Paulo: Edusp, 2004.

MURAT, Rodrigo. Zezé Motta, muito prazer. Rio de Janeiro: Imprensa Oficial, 2005.

PINSKY, Carla; PEDRO, Joana. (Orgs.). Nova história das mulheres no Brasil. São Paulo: Contexto, 2013.

SANTOS, Joaquim Felicio dos. Memórias do districto diamantino da comarca do Serro Frio: (provincia de Minas Geraes). Rio de Janeiro: Typ. Americana, 1868.

ROSA, Sonia. Quando a escrava Esperança escreveu uma carta. Rio de Janeiro: Pallas, 2012.

SENA, Ernesto. Rascunhos e perfis. Brasília, DF: Editora da UnB, 1983.

SCHWARZ, R. Autobiografia de Luiz Gama. Novos Estudos, n. 25, p. 136-141, 1989.

SILVA, Alexandra Lima da. Narrativas de vida de ex-escravos como fonte/objeto para a história da educação. In: VASCONCELOS, Maria Celi; CORDEIRO, Verbena Maria Rocha; VICENTINI, Paula Perin. (Orgs.). (Auto)biografia, literatura e história. Curitiba: CRV, 2014. v. 1. p. 129-145.

SOUZA, Elizeu C. de.; MIGNOT, Ana C. V. (Orgs.). Histórias de vida e formação de professores. Rio de Janeiro: Quartet; FAPERJ, 2008.

SOUZA, Elizeu C. de. 0 Conhecimento de si: estágio e narrativa de formação de professores. Rio de Janeiro: DP\&A Editora, 2006. v. 1.

SOUZA, Elizeu C. de.; DEMARTINI, Z. B. F.; GONÇALVES, $M$. (Orgs.). Gênero, diversidade e resistência: escritas de si e experiências de empoderamento. Curitiba: CRV, 2016. v. 6.

SOUZA, Maria Cecília. Preto no branco: a trajetória de escritor de Luiz Gama. In: VIDAL, Diana \& HILS-
DORF, Maria Lucia Spedo. Brasil 500 Anos. Tópicas em História da Educação. São Paulo: EdUSP, 2001. p. 97-115.

VENANCIO, Giselle. Em primeira pessoa. In: VENANCIO, G. M.; SECRETO, M. V.; RIBEIRO, G. S. Cartografias da cidade (in)visivel. Setores populares, cultura escrita, educação e leitura no Rio de Janeiro. Rio de Janeiro: Mauad X, 2017.

XAVIER, Giovana; FARIAS, Juliana; GOMES, Flávio. (Orgs.). Mulheres negras no Brasil escravista e do pós-emancipação. São Paulo: Selo Negro, 2012.

XAVIER, Giovana. Entre personagens, tipologias e rótulos da 'diferença': a mulher escrava na ficção do Rio de Janeiro no século XIX. In: XAVIER, Giovana; FARIAS, Juliana; GOMES, Flávio. (Orgs.). Mulheres negras no Brasil escravista e do pós-emancipação. São Paulo: Selo Negro, 2012. p. 67-83.

\section{Manuscritos}

Arquivo Geral da Cidade. Carta de Maria Rosa, Maria Rosa, 1886, Arquivo Geral da Cidade.

Biblioteca Nacional, manuscritos. Carta da escrava Paula da Cunha Conceição ao Imperador, fevereiro de 1825.

Biblioteca Nacional, manuscritos. Requerimento de Mathilde Lauriana 1821.

Biblioteca Nacional, manuscritos. Requerimento da escrava Ludovina, 1841.

Biblioteca Nacional, manuscritos. Requerimento da escrava Benedita, 1858.

Biblioteca Nacional, manuscritos. Requerimento da escrava Madalena, 1821.

Biblioteca Nacional, manuscritos. Carta da escrava Vitória Maria ao Imperador, 1851.

\section{Filmes}

Xica da Silva. Direção: Cacá Diegues, 1976.

Quanto vale ou é por quilo? Direção: Sergio Bianchi, 2005.

Recebido em: 14.06.2018

Aprovado em: 30.08 .2018 
Alexandra Lima da Silva é doutora em Educação pela Universidade do Estado do Rio de Janeiro (UERJ), com período de bolsa sanduíche financiado pela CAPES na Universidad de Alcalá e bolsa doutorado nota 10 da Fundação Carlos Chagas Filho de Amparo à Pesquisa do Estado do Rio de Janeiro (FAPERJ). Atualmente é professora visitante na University of Illinois, com bolsa CAPES. Professora adjunta da Faculdade de Educação e do ProPed/UERJ da UERJ, Campus Maracanã. Pesquisadora da FAPERJ no programa Jovem Cientista do Nosso Estado desde 2015 e bolsista de produtividade UERJ/ FAPERJ (Prociência 2017). e-mail: alexandralima1075@gmail.com

R. São Francisco Xavier, 524 - Sala 1006 A - Maracanã, Rio de Janeiro - RJ. CEP: 20550-900. 